\section{Comparison of parents knowledge of bad habits and the severity maloclusion of children in schools with different social levels}

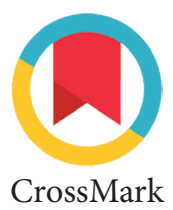

\author{
Baharuddin M. Ranggang, ${ }^{*}$ Riana N. Armedina
}

\title{
Abstract
}

Objective: To knows comparison of the level of knowledge of parents of bad habits and the severity of malocclusion children at school with a different social level, namely Elementary School of Kera-Kera Settlement (SD Inpres Kera-Kera) and Al-Biruni Intgrated Islamic Elementary School of Makassar City (SDIT Al-Biruni Makassar). Material and Methods: The sampling method used is purposive sampling. Measurement of the level of parental knowledge using a questionnaire, the severity of children's malocclusion using the Occlusion Feature Index (OFI) method.

Results: In the SD Inpres Kera-Kera, the level of knowledge of parents with Low criteria of $63.6 \%$, the severity of malocclusion of children with a very mild $\mathrm{OFI}$ score of $2.3 \%$, mild criteria of $34.1 \%$, medium criteria $59,1 \%$, and the weight criteria are $4.5 \%$. SDIT Al-Biruni assessment of the level of knowledge of good parents as much as $81.4 \%$, the severity of malocclusion with an $\mathrm{OFI}$ score of very mild criteria as much as $5.1 \%$, mild criteria as much as $49.2 \%$, medium criteria $42.4 \%$, and severe criteria as much as $34 \%$.

Conclusion: There is a difference in the knowledge of parents of SD Inpres Kera-Kera and SDIT Al-Biruni parents. Parent's knowledge of bad habits and malocclusion at SDIT Al-Biruni Makassar is far better than that of SD Inpres Kera-Kera
Department of Orthodontics, Faculty of Dentistry, Hasanuddin University, Makassar, Indonesia
*Correspondence to:

Baharuddin M. Ranggang, Department of Orthodontics, Faculty of Dentistry, Hasanuddin University, Makassar, Indonesia

baharfkguh@gmail.com

Received: 3 January 2020 Revised: 5 February 2020 Accepted: 28 March 2020 Available Online: 1 April 2020
Keywords: Bad habits, Malocclusion, OFI method, Parental knowledge

Cite this Article: Ranggang BM, Armedina RN. 2020. Comparison of parents knowledge of bad habits and the severity maloclusion of children in schools with different social levels. Journal of Dentomaxillofacial Science 5(1): 48-51. D0I: 10.15562/jdmfs.v5i1.1052

\section{Introduction}

Malocclusion is a condition where there are differences in normal form or the occurrence of deviations from the normal relationship of teeth in the arch of the same or opposite teeth. ${ }^{1-3}$ Mallocation is a health problem that has received full attention, according to WHO malocclusion has become the third most common oral disease, after dental caries and periodontal disease. ${ }^{4}$ The prevalence of malocclusion in Indonesia has reached $80 \%$ of the population is the population of the Indonesian people and ranks third after caries and periodontal disease, because of prevalence is high malocclusion is considered a public health problem that can interfere with the quality of life of patients, impede social interaction them, and influences patient psychology. ${ }^{4}$ One of the causes of malocclusion is bad habits, bad habits that are carried out repeatedly and continuously during the development of the jaw will result in malocclusion. ${ }^{2}$ Bad habits such as finger sucking / nipples, nail biting, lip biting, mouth breathing, and tongue sticking habits have an impact on the prevalence of malocclusion, especially in children. Examples of bad habits such as finger sucking have a high chance of disrupting tooth position, disrupting bone growth patterns that can change craniofacial growth which is known to cause malocclusion, this habit can have the effect of malocclusion of open anterior bite. There was a significant relationship between the development and prevalence of malocclusion with the prevalence of bad habits. ${ }^{1,5}$ The results of a study in children aged 7-15 years who have oral bad habits showed about $80 \%$ of children suffer from malocclusion, both class I, class II and class III malocclusions. According to Singh, children who have oral bad habits, especially finger sucking, tend to have class II malocclusions. This proves a correlation that oral bad habits cause good malocclusions that do not have to be treated and that must be treated if they are not controlled. ${ }^{6}$

The severity of malocclusion can be seen in the period of mixed teeth, namely the age of 8-10 years because this period is the most important period in the development of teeth in children. According to Jabur and Miyasif research, ages 8-9 years are the age group that shows the highest oral bad habits with around $35,45 \%$ of children have oral bad habits. This is also supported by the results of research from Yohana and Riyanti, which are 8-year-old children are the group that most often have oral bad habits with a percentage of $22.87 \% .^{6}$

Impacts that arise as a result of malocclusion can have an impact on the physiology, psychology and social of children. Malocclusion can disrupt the 
mastication system, pronunciation, facial posture, cause temporomandibular disorder, disturb the aesthetic, and social of children because of shame to smile, so that the consequences of malocclusion can indirectly reduce the quality of life of children. ${ }^{3,4}$

Parental knowledge about adverse oral bad habits is a factor that must be considered because parents' ignorance can be the cause of the occurrence of dentofacial anomalies in children. Parents as one of the main educators in a child's life can unconsciously influence the survival or failure of a bad habit and also in the child's oral health. The influence of parents' knowledge and attitudes towards oral bad habits determines whether or not these habits are carried out continuously. Parents can provide motivation and education to their children to stop these bad habits. ${ }^{5,6}$

To measure the severity of children's malocclusion in epidemiological studies, a number of malocclusion indices have been proposed and implemented, namely Occlusion Feature Index (OFI), Malalignment Index (Mal I), Handicapping Labio-lingual Deviation Index (HLD Index), Handicapping Malocclusion Assessment Index (HMA Index), Treatment Priority Index (TPI), Occlusal Index (OI). Most of these indices note specific conditions. One of the malocclusion indices, the Occlusal Feature Index (OFI), measures malocclusion based on crammed teeth, interdigitation of cusps of teeth, overlapping bites and bite distance. This method is simple and objective and does not require complicated diagnostic equipment such as the gnathostatic model and cephalometric devices. Evaluated this method and the results of their research prove that the assessment of the severity of malocclusion by orthodontists is subjective and the assessment by public health specialists using OFI results is very close. ${ }^{7}$

Researchers classify schools with different social levels by assessing the external and internal of the school, which is based on the curriculum, school programs, location of school, school funding, and school facilities. Based on the description above, by assessing the knowledge of parents and malocclusions in their children the researcher wants to make a study of the comparison of parents' knowledge of bad habits with the prevalence of malocclusion of children in schools with different social levels, in Elementary School of Kera-Kera Settlement (SD Inpres Kera-Kera) and Al-Biruni Intgrated Islamic Elementary School of Makassar City (SDIT Al-Biruni Makassar).

\section{Material and Methods}

This type of research is observational descriptive. Population of research were children age developmental age of 9-12 years and their parents. The sampling method used was Purposive Sampling.

This research was conducted in Makassar City, at Elementary School of Kera-Kera Settlement (SD Inpres Kera-Kera) and Al-Biruni Intgrated Islamic Elementary School of Makassar City (SDIT Al-Biruni Makassar) in the range of April- August 2019. Data were obtained through clinical examination of the oral cavity to assess the severity of a child's malocclusion using the Occlusion Feature Index (OFI) method and administering a questionnaire to parents. Statistical tests use the Gamma Correlation Test of two ordinal data to see the correlation of parents' level of knowledge with bad habits with the severity of a child's malocclusion, and the Mann Whitney Test to see a comparison between the two schools.

Tools and materials used in the form of Cheek Retractor, Oral Diagnostic Set, camera, malocclusion assessment sheet, questionnaire, pen, mask, handscoen, povidone iodine, alcohol.

This study was approved by the Ethics Committee, Faculty of Dentistry, University of Hasanuddin based attachment Number: 0229 / PL.09 / KEPK FKG-the Hospital UNHAS / 2019, and approved by the Education Department Government of Makassar based research Permit No. 070/0616/DP/VII/2019.

\section{Results}

The study was conducted at SD Inpres Kera-Kera and SDIT Al-Biruni Makassar with a total sample of 103 people (44 people from SD Inpres KeraKera, 59 from Al-Biruni Makassar SDIT) who met the research inclusion criteria and were taken as research subjects table 1 .

Figure 1 is attached that $53.3 \%$ of parents do not know about malocclusion in children (Q1), 43\% of parents agree that deciduous problems can affect permanent teeth (Q2), 38.6\% of parents know that maintaining healthy deciduous teeth healthy and regular can prevent malocclusion in children (Q3), $56.9 \%$ of parents do not know that bad habits can affect teeth in children (Q4), 61.3\% of parents know finger sucking is a bad habit that can affect teeth (Q5A), 29.5\% of parents know lip sucking / biting is a bad habit that can affect teeth (Q5B), 27.2\% of parents know breathing through the mouth is a bad habit that can affect teeth (Q5C), 34.1\% of parents know nail biting is a bad habit that can affect teeth (Q5D), 36.3\% parents know sticking out tongue is a bad habit that can affect teeth (Q5E), 41\% of parents know bruxism is a bad habit that can affect teeth (Q5F).

Figure 2 is attached that $19.7 \%$ of parents do not know about malocclusion in children (Q1), 78\% of 
Table 1 The frequency of the level of children's malocclusion and the level of Parental Knowledge in SD Inpres Kera-Kera

\begin{tabular}{llcc}
\hline Variable & & Frequency & $\%$ \\
\hline Severity of Child Malocclusion & Verymild & 1 & 2.3 \\
& Mild & 15 & 34.1 \\
& Medium & 26 & 59.1 \\
& Weight & 2 & 4.5 \\
Total & & 44 & 100.0 \\
Parental Knowledge Level & Low & 28 & 63.6 \\
& Good & 16 & 36.4 \\
Total & & 44 & 100.0 \\
\hline
\end{tabular}

Table 2 Frequency OFI score of children and Parents' Knowledge Level at SDIT Al-Biruni Makassar

\begin{tabular}{llcc}
\hline Variable & & Frequency & $\%$ \\
\hline OFI score & Very mild & 3 & 5.1 \\
& Mild & 29 & 49.2 \\
& Medium & 25 & 42.4 \\
& Weight & 2 & 3.4 \\
Total & & 59 & 100.0 \\
Parental Knowledge Level & Low & 11 & 18.6 \\
& Good & 48 & 81.4 \\
Total & & 59 & 100.0 \\
\hline
\end{tabular}

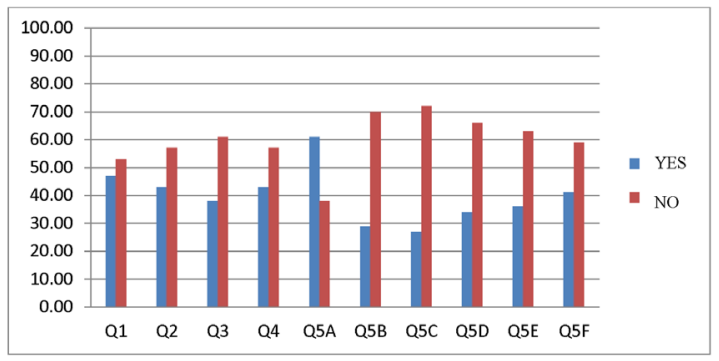

Figure 1 Percentage of parents' level of knowledge based on questionnaires at SD Inpres Kera-Kera

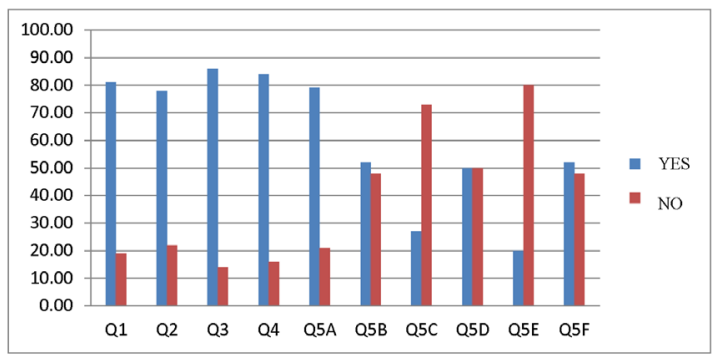

Figure 2 Percentage level of parental knowledge based on questionnaires at SDIT Al-Biruni Makassar parents agree that deciduous problems can affect permanent teeth (Q2), 86.4\% of parents know that maintaining healthy deciduous teeth healthy and regular can prevent malocclusion in children $(\mathrm{Q} 3)$, $84.7 \%$ of parents know that bad habits can affect teeth in children (Q4), 79.6\% of parents know finger sucking is a bad habit that can affect teeth ( Q5A), $52.5 \%$ of parents know sucking / biting on the lips is a bad habit that can affect teeth (Q5B), 27.1\% of parents know breathing through the mouth is a bad habit that can affect teeth (Q5C), 50.8\% parents know nail biting is a bad habit that can affect teeth (Q5D), 20.3\% parents know sticking out tongue is a bad habit that can affect teeth (Q5E), 52.5\% parents know bruxism is a bad habit that can affect gear (Q5F) table 2.

\section{Discussion}

One of the causes of malocclusion is bad habits, bad habits that are done repeatedly and continuously during the development of the jaw will result in malocclusion. ${ }^{2}$ Bad habits such as finger sucking / nail biting, nail biting, lip biting, mouth breathing, and tongue sticking habits have an impact on the prevalence of malocclusion, especially in children. The results study in children aged 7-15 years who have oral bad habits show that about $80 \%$ of children suffer from malocclusion, be it class I, class II, and class III malocclusions. Children who have oral bad habits, especially finger sucking, tend to have class II malocclusions. This proves a correlation that oral bad habits cause good malocclusions that do not have to be treated and that must be treated if they are not controlled. ${ }^{8}$

Parents as one of the main educators in a child's life can unconsciously influence the survival or failure of a bad habit and also in the child's oral health. The influence of parents' knowledge and attitudes towards oral bad habits determines whether or not these habits are carried out continuously. ${ }^{9}$

There is no significant relationship ( $\mathrm{p}=0.488$, $\mathrm{p}>0.05)$, the level of parental knowledge with the severity of a child's malocclusion is inversely related to the strength of a weak relationship in SD Inpres Kera-Kera. Elementary school children in Denpasar with the result that there was no correlation between the level of parental knowledge and the severity of malocclusion caused by bad habits, showed no relationship between parent's knowledge level with child malocclusion.

There is a significant relationship (p: 0.003, $\mathrm{p}<0.05$ ), the level of parental knowledge with the severity of child malocclusion is inversely related 
to the strength of the strong relationship at SDIT Al-Biruni Makassar.

The results of this study can be concluded with several possibilities. First is because the malocclusion is also supported by other factors outside of bad oral habits, secondly, malocclusion is not a priority for parents in dealing with children's dental and mouth problems.

In the Mann Whitney test results obtained a sig value of 0,000 . This shows that there is a difference in knowledge between parents of SD Inpres KeraKera and SDIT Al-biruni parents. Knowledge of parents SDIT Al-Biruni about the habits bad far more better than the knowledge of parents SD Inpres Kera-Kera, it is based of average value obtained. On average knowledge of parents SDIT Al-Biruni is much more higher than the average knowledge of parents SD Inpres Kera-Kera. ${ }^{10}$

The results of this study can be concluded with the possibility of parental knowledge influenced by several factors such as work and social environment.

\section{Conclusion}

Based on research results comparing the level of parental knowledge of bad habits and the severity of malocclusion of children in schools with different social levels, it can be concluded: parents SDIT Al-Biruni Makassar who has knowledge of Good about bad habits and malocclusion that is equal to $81,4 \%$. While parents in SD Inpres Kera-Kera who have good knowledge about bad habits and malocclusion are $36.4 \%$; there is a significant difference regarding the level of parental knowledge of bad habits in schools with a social level of dressing; there is no significant relationship between the level of parental knowledge of bad habits with the severity of children's malocclusion in SD Inpres KeraKera. While at SDIT Al-Biruni Makassar there is a significant relationship between the level of parents' knowledge of bad habits and the severity of children's malocclusion.

\section{Acknowledgment}

None.

\section{Conflict of Interest}

The authors report no conflict of interest.

\section{References}

1. Shouq AA. Meta-analysis of prevalence of bad habits and relationship with prevalence of malocclusion. EC Dent Sci 2017;11: 4 .

2. Channel N, Rana M, Dharwan A, et al. Assessment of frequency of occurrence of malocclusion among known paediatric population: a clinical study. J Adv Med Dent Sci Res 2018;6: 37-39.

3. Dutra SR, Pretti H, Martins MT, et al. Impact of malocclusion on the quality of life of children aged 8 to 10 years. Dental Press J Orthod 2018;23: 46-53.

4. Jefferson Y. Mouth breathing: adverse effect on facial growth, health, academics, and behavior. East Hanover: Academy of General Dentistry; 2010. p. 18-23.

5. Nabila CR. Relationship of parents' knowledge with the condition of malocclusion in children who have oral bad habits. J Syiah Kuala Dent Soc 2017;2: 12-18. (In Indonesia)

6. Herawati H, Sukma N, Utami RD. Relationships between deciduous teeth premature loss and malocclusion incidence in elementary school in Cimahi. J Med Health 2015;1: 156-169.

7. Suminy D, Zen Y. Relationship between malocclusion and airway obstruction. Kedokteran Gigi Scient J Dentist 2007;22: 32-33. (In Indonesia)

8. Feroza NA, Fajar KDK, Wibowo D. The relationship between bad habits of breathing through the mouth and the severity of malocclusion in the Public Middle School 4 Banjarbaru and the Public Middle School 4 Banjarbaru. Dentino 2017;2: 39-43. (In Indonesia)

9. Deepika P. Parental awareness about maloclussion in their children: a common yet unknown disorder. J Dent Med Sci 2018;17: 34-37.

10. Winarti TM, Rikmasari R. Bad posture habits that interfere with health of temporomandibular joint. J Dentomaxillofac Sci 2011;10: 196-201.

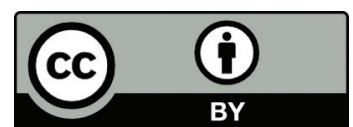

This work is licensed under a Creative Commons Attribution 